\title{
Clinical study on the diagnosis of porcine streptococcal meningitis with negative blood and cerebrospinal fluid culture by next-generation sequencing
}

Eryi Zhao ${ }^{1 \dagger}$, Daimei Wang ${ }^{2 \dagger}$, Na Li ${ }^{3 *}$, Shixiong Huang ${ }^{1}$, Zhongyan Zhao ${ }^{1}$, Shijun $\mathrm{Hu}^{1}$, Xiangying He ${ }^{1}$ and Guoqiang Wen'

\begin{abstract}
Background: Streptococcus suis (Ss) is a Gram-positive and anaerobic zoonotic pathogen that is susceptible to all populations and can cause meningitis, septicemia, endocarditis and arthritis in humans.

Methods: In this study, patients with meningitis who were admitted to our hospital with negative blood and cerebrospinal fluid culture were divided into a next-generation sequencing group and a control group. In the nextgeneration sequencing group, we used the next-generation sequencing method to detect pathogenic bacteria in the patients' cerebrospinal fluid. In the control group, we used blood and cerebrospinal fluid bacterial culture method to detect pathogenic bacteria in the patients' cerebrospinal fluid. The detection rates of pathogenic bacteria in the cerebrospinal fluid of the two groups were compared and analyzed.

Results: A total of 18 patients were included in this study, including 8 patients in the next-generation sequencing group and 10 patients in the control group. The mean age $(P=0.613)$ and mean disease duration $(P=0.294)$ were similar in both groups. Patients in the next-generation sequencing group had a leukocyte count of $13.13 \pm 4.79 \times 10^{9}$, a neutrophil percentage of $83.39 \pm 10.36 \%$, and a C-reactive protein level of $134.95 \pm 107.69 \mathrm{mg} / \mathrm{L}$. Patients in the control group had a temperature of $38.32 \pm 1.07$, a leukocyte count of $8.00 \pm 2.99 \times 10^{9}$, and a neutrophil percentage of $74.61 \pm 8.89 \%$, and C-reactive protein level was $4.75 \pm 6.8 \mathrm{mg} / \mathrm{L}$. The statistical results showed that the leukocytes $(P=0.013)$ and $C$-reactive protein levels $(P=0.001)$ were significantly higher in the patients of the next-generation sequencing group than in the control group. No statistically significant differences were seen in body temperature and neutrophil percentage between the two groups $(P>0.05)$. The incidence of intracranial pressure and meningeal irritation signs were similar in the two groups $(P>0.05)$. The detection rate of Streptococcus suis in the cerebrospinal fluid of patients in the next-generation sequencing group was 100\%, and the detection rate of Streptococcus suis in the cerebrospinal fluid of the control group was $0 \%$.
\end{abstract}

Conclusion: The detection rate of Streptococcus suis infection in cerebrospinal fluid by next-generation sequencing was significantly higher than that by blood and cerebrospinal fluid bacterial culture. Therefore, the diagnosis

\footnotetext{
*Correspondence: Idong2333@aliyun.com

†Eryi Zhao and Daimei Wang contributed equally to this study

${ }^{3}$ Department of Pharmacy, Qianjiang Central Hospital of Chongqing, No. 63 of Road 9, Chengxi Street, Qianjiang District, Chongqing 409099, China

Full list of author information is available at the end of the article
}

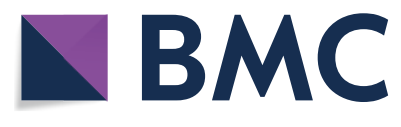

(c) The Author(s) 2021. Open Access This article is licensed under a Creative Commons Attribution 4.0 International License, which permits use, sharing, adaptation, distribution and reproduction in any medium or format, as long as you give appropriate credit to the original author(s) and the source, provide a link to the Creative Commons licence, and indicate if changes were made. The images or other third party material in this article are included in the article's Creative Commons licence, unless indicated otherwise in a credit line to the material. If material is not included in the article's Creative Commons licence and your intended use is not permitted by statutory regulation or exceeds the permitted use, you will need to obtain permission directly from the copyright holder. To view a copy of this licence, visit http://creativecommons.org/licenses/by/4.0/. The Creative Commons Public Domain Dedication waiver (http://creativeco mmons.org/publicdomain/zero/1.0/) applies to the data made available in this article, unless otherwise stated in a credit line to the data. 
of porcine streptococcal meningitis by next-generation sequencing method is worthy of clinical promotion and application.

Keywords: Diagnosis, Next-generation sequencing, Streptococcal meningitis

\section{Introduction}

Streptococcus suis (Ss) is a Gram-positive and anaerobic zoonotic pathogen that is susceptible to all populations and can cause meningitis, septicemia, endocarditis and arthritis in humans. Among them, meningitis is the most common, and most of them can have severe sequelae of cochlear and vestibular nerve damage [1]. Its invasion of the central nervous system through the blood-brain barrier or blood-cerebrospinal fluid barrier via cerebral microvascular epithelial cells or choroidal epithelial cells leads to inflammation of the meningeal brain parenchyma [2], and the main causative risk factors include occupational exposure to pigs, raw pork, or consumption of raw pig meat products [3].

Cerebrospinal fluid pathogenic bacteria with nextgeneration sequencing (NGS) technology is an emerging molecular diagnostic method for rapid detection of intracranial pathogens [4], which has unique advantages in unexplained pathogenic infections. Therefore, this study intends to investigate the diagnostic value of nextgeneration sequencing (NGS) in the diagnosis of porcine streptococcal meningitis with negative blood and cerebrospinal fluid culture.

\section{Data and methods}

\section{Study subjects}

Patients with meningitis who were admitted to our hospital with negative blood and cerebrospinal fluid culture were the main subjects of this study, and were divided into next-generation sequencing group and control group. This study is in accordance with the Declaration of Helsinki of the World Medical Association and has been approved by the ethics committee of our hospital, and all patients signed an informed consent form.

\section{Inclusion and exclusion criteria}

Inclusion criteria are: (1) patients diagnosed with meningitis; (2) age > 18 years; and (3) patients who had signed the informed consent form. Exclusion criteria are: (1) patients with advanced malignancy and (2) patients with incomplete information.

\section{Study methods}

In the next-generation sequencing group, we used the next-generation sequencing method to detect pathogenic bacteria in the patients' cerebrospinal fluid by next-generation sequencing equip (USA, Illumina Nextseq550). In the control group, we used blood and cerebrospinal fluid bacterial culture method to detect pathogenic bacteria in the patients' cerebrospinal fluid. The detection rates of pathogenic bacteria in the cerebrospinal fluid of patients in the two groups were compared and analyzed.

\section{Cerebrospinal fluid detection method}

About $2-3 \mathrm{~mL}$ of cerebrospinal fluid was collected by lumbar puncture and stored at $-20{ }^{\circ} \mathrm{C}$ after aseptic sealing. DNA was extracted according to the DNA extraction kit (Tiangen (Beijing) Biotech Co., Ltd, Tiangen DNA Mini kit DP316). Next-generation sequencing (NGS) technology was used to detect pathogens in the cerebrospinal fluid.

\section{Main observation indexes}

The main observation indexes of this study included gender, age, disease duration, body temperature, leukocytes, neutrophil percentage, C-reactive protein level, intracranial pressure, and cerebrospinal fluid test.

\section{Statistical analysis}

SPSS 20.0 statistical software was used for data processing in this study, and the measurement data were expressed as mean \pm standard deviation $(\bar{x} \pm s)$. Count data were expressed as percentages (\%). The $t$ test was used for comparison between two groups obeying normal distribution; the non-parametric test was used for comparison between groups not obeying normal distribution. Counting data were tested by Chi-square test. $P<0.05$ was considered a statistically significant difference.

\section{Results}

\section{General information}

A total of 18 patients were included in this study, including 8 patients in the next-generation sequencing group and 10 patients in the control group. The mean age of patients in the next-generation sequencing group was $54.25 \pm 8.60$ years, and the mean duration of disease was $5.88 \pm 4.64$ days. The mean age of patients in the control group was $50.10 \pm 21.31$ years, and the mean disease duration was $9.50 \pm 8.46$ days. There was no significantly difference about mean age $(P=0.613)$ and mean duration of illness $(P=0.294)$ between the two groups. 


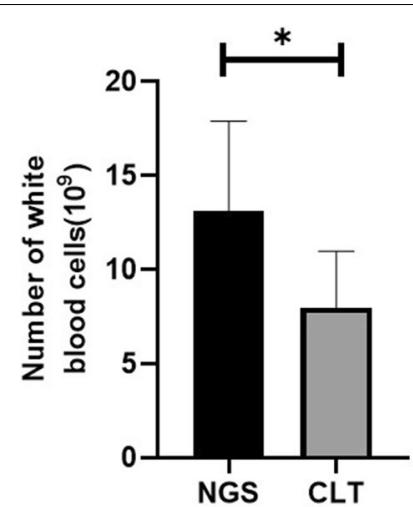

Fig. 1 Comparison of leukocyte count between the two groups of patients

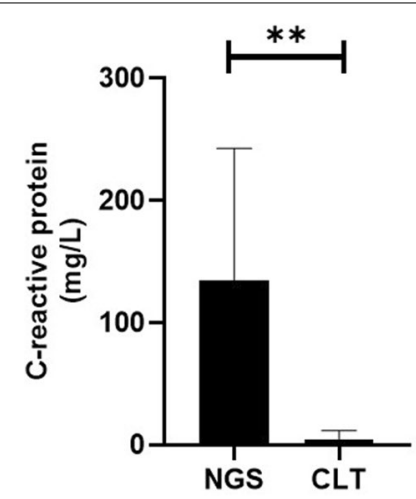

Fig. 2 Comparison of $\mathrm{C}$-reactive protein levels between the two groups of patients

\section{Comparison of infection indicators between the two groups of patients}

The results showed that the white blood cell count was significantly higher in the diphtheria group than control group $\left(13.13 \pm 4.79 \times 10^{9}\right.$ vs. $8.00 \pm 2.99 \times 10^{9}$, $P=0.013$ ), the C-reactive protein level was significantly higher in the diphtheria group than control group $(134.95 \pm 107.69 \mathrm{mg} / \mathrm{L}$ vs. $4.75 \pm 6.8 \mathrm{mg} / \mathrm{L}$, $P=0.001)$. The body temperature $\left(38.95 \pm 0.49{ }^{\circ} \mathrm{C}\right.$ vs. $\left.38.32 \pm 1.07{ }^{\circ} \mathrm{C}, P=0.143\right)$ and neutrophil percentage $(83.39 \pm 10.36 \%$ vs. $74.61 \pm 8.89 \%, P=0.071)$ were similar in both the groups (Figs. 1, 2).

\section{Results of cerebrospinal fluid testing in the two groups of patients}

The intracranial pressure of patients in the next-generation sequencing group was $205.63 \pm 66.09 \mathrm{mmH} 2 \mathrm{O}$, $190.70 \pm 53.55 \mathrm{mmH} 2 \mathrm{O}$ in the control group. $100 \%$ of patients in the next-generation sequencing group and $80 \%$ of patients in the control group had meningeal irritation signs. The statistical results showed that the incidence of intracranial pressure and meningeal irritation signs were similar in the two groups $(P>0.05)$. The detection rate of Streptococcus suis in the cerebrospinal fluid of patients in the next-generation sequencing group was $100 \%$, and the detection rate of Streptococcus suis in the cerebrospinal fluid of the control group was $0 \%$ (Fig. 3).

\section{Discussion}

Porcine streptococcal meningitis is the most predominant type of human infection with porcine streptococcal disease, which has been outbreaks and epidemics in Sichuan and Jiangsu in China, but is disseminated in other provinces, and rare cases are reported in Hainan [5]. The diagnosis of this disease is based on the epidemiological history, clinical manifestations, and confirmation of diagnosis requires positive blood and cerebrospinal fluid culture of Streptococcus suis [6], but due to factors such as low blood and cerebrospinal fluid bacteria, insufficient sampling or pre-treatment with antibiotics, resulting in positive blood and cerebrospinal fluid culture is not high, the positive rate of blood bacterial culture is about $32 \%$, the positive rate of cerebrospinal fluid bacterial culture is $18.5 \%$, and negative blood and cerebrospinal fluid bacterial culture increases the difficulty of clinical diagnosis [7].

Common signs and symptoms of porcine streptococcal meningitis include fever, headache, and neck stiffness [8-11]. Bilateral hearing impairment occurs early in the disease and the incidence can be as high as $66.4 \%$ [12], mainly due to labyrinthitis. The cellular classification of the cerebrospinal fluid in this disease is dominated by multiple nucleated cells, which may be misdiagnosed as viral meningitis or tuberculous meningitis once it is quickly converted to single nucleated cells or lymphocytes predominant after antibiotic treatment [13].

Next-generation sequencing technology, as an emerging molecular diagnostic method in current clinical practice [14-18], has been applied in various infectious disease areas in clinical practice $[19,20]$. Therefore, the present study was proposed to investigate the diagnostic value of next-generation sequencing (NGS) in blood and cerebrospinal fluid culture-negative porcine streptococcal meningitis. A total of 18 patients were included in this study, including 8 patients in the next-generation sequencing group and 10 patients in the control group. The results of the study showed that the detection rate of Streptococcus suis in the cerebrospinal fluid of patients in the next-generation sequencing group was $100 \%$, and the detection rate of Streptococcus suis in the cerebrospinal fluid of the control group was $0 \%$. Therefore, when the pathogenic bacteria cannot be detected by blood and 

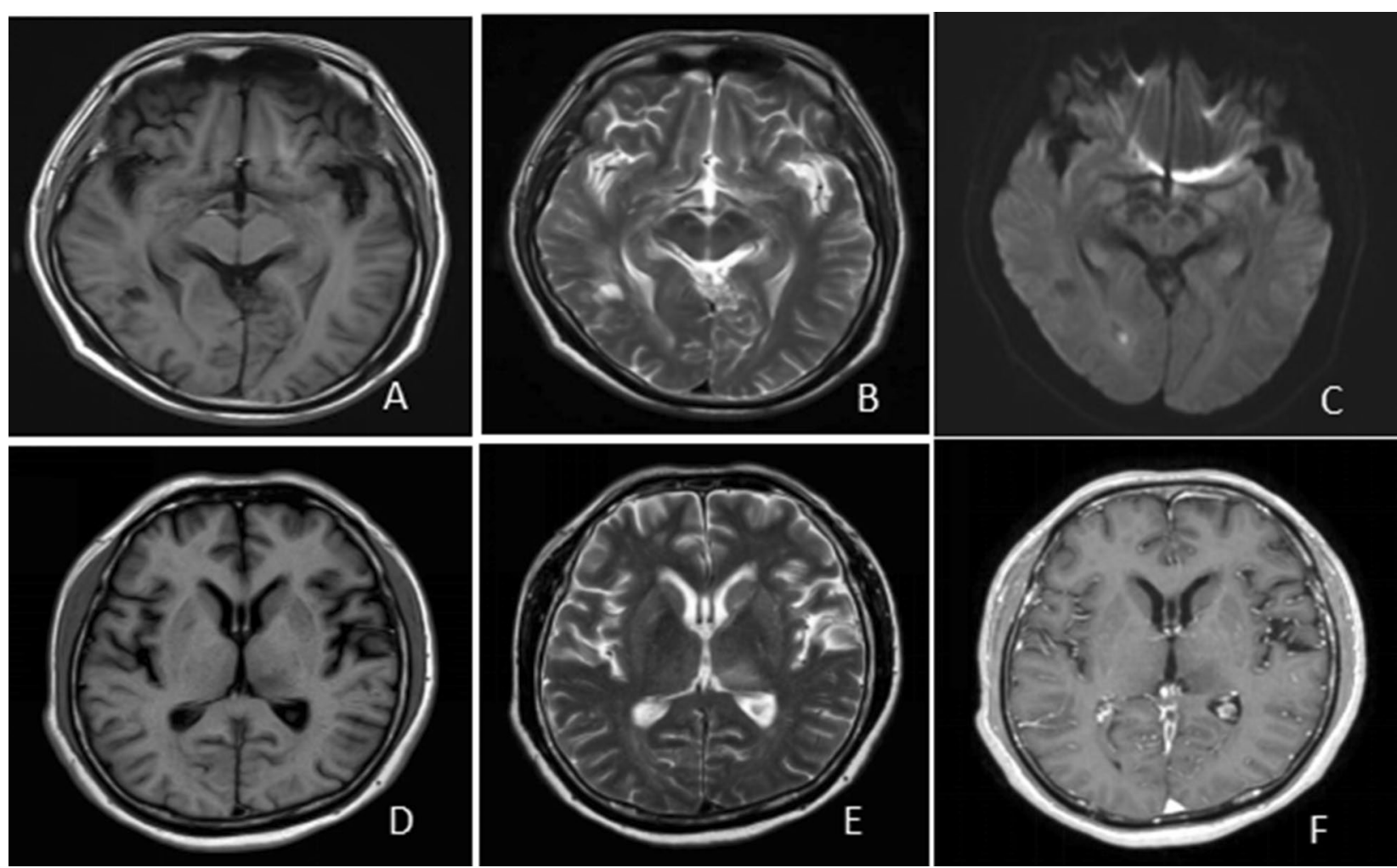

Fig. 3 The results of cranial imaging of porcine streptococcal meningitis. A-C The cranial MRI results of one patient, showing an abnormal lesion in the right occipital lobe parietal ventricle with small abscess formation; D-F The cranial MRI results of another patient, showing inflammatory lesions in the left thalamus and basal ganglia region

cerebrospinal fluid bacterial culture methods, the pathogenic bacteria in cerebrospinal fluid can be detected by next-generation sequencing method. In this study, the results showed that the leukocytes and C-reactive protein levels were significantly higher in the patients of the next-generation sequencing group than control group. The reason maybe due to the specific clinical characteristics, such as complicated with other bacterial infections. However, other reasons still needs further research.

The present study still has the following shortcomings. First, this study is a single-center clinical study, and follow-up multicenter clinical studies are still needed for further investigation. Second, the sample size included in this study was small, and further studies with larger sample size are needed.

\section{Conclusion}

The detection rate of Streptococcus suis infection in cerebrospinal fluid by next-generation sequencing was significantly higher than that by blood and cerebrospinal fluid bacterial culture. Therefore, when clinically suspected streptococcal meningitis, but the cerebrospinal fluid culture is negative, we can use this next generation of sequencing to confirm the diagnosis, so as to improve the clinical diagnostic efficiency of streptococcal meningitis. The diagnosis of Streptococcus suis meningitis by next-generation sequencing method is worthy of clinical application.

\section{Abbreviations}

NGS: Next-generation sequencing; Ss: Streptococcus suis.

\section{Acknowledgements}

Not applicable.

\section{Authors' contributions}

ZEY and WDM conceived of the study and LN, HSX and ZZY participated in its design and coordination, and HSJ, HXY and WGQ helped to draft the manuscript. All the authors read and approved the final manuscript.

\section{Funding}

Supported by Scientific research projects of health industry in Hainan Province (No. 20A200223).

\section{Availability of data and materials}

All data generated or analyzed during this study are included in this published article. 


\section{Declarations}

\section{Ethics approval and consent to participate}

This study was conducted in accordance with the Declaration of Helsinki and approved by the ethics committee of our hospital. All the participants had signed the informed consent.

\section{Consent for publication}

Not applicable.

\section{Competing interests}

All the authors had no any personal, financial, commercial, or academic conflicts of interest separately.

\section{Author details}

1 Department of Neurology, Hainan General Hospital, Hainan Affilicated Hospital of Hainan Medical University, Haikou 570311, Hainan, China. ${ }^{2}$ Department of Pharmacy, Hainan General Hospital, Hainan Affilicated Hospital of Hainan Medical University, Haikou 570311, Hainan, China. ${ }^{3}$ Department of Pharmacy, Qianjiang Central Hospital of Chongqing, No. 63 of Road 9, Chengxi Street, Qianjiang District, Chongqing 409099, China.

Received: 27 May 2021 Accepted: 15 July 2021

Published online: 03 August 2021

\section{References}

1. Lun ZR, Wang QP, Chen XG, Li AX, Zhu XQ. Streptococcus suis: an emerging zoonotic pathogen. Lancet Infectious Diseases. 2007;7:201-9.

2. Dutkiewicz J, Zając V, Sroka J, Wasiński B, Cisak E, Sawczyn A, et al. Streptococcus suis: a re-emerging pathogen associated with occupational exposure to pigs or pork products. Part II-Pathogenesis. Ann Agric Environ Med. 2018;25:186-203.

3. Takeuchi D, Kerdsin A, Akeda Y, Chiranairadul P, Loetthong P, Tanburawong N, Areeratana $\mathrm{P}$, et al. Impact of a food safety campaign on Streptococcus suis infection in humans in Thailand. Am J Trop Med Hyg. 2017;96:1370-7.

4. Brown JR, Bharucha T, Breuer J. Encephalitis diagnosis using metagenomics: application of next generation sequencing for undiagnosed cases. J Infect. 2018;76:225-40.

5. Hebowicz M, Jakubowski P, Smiatacz T. Streptococcus suis meningitis: epidemiology, clinical presentation and treatment. Vector Borne Zoonotic Dis. 2019;19:557-62.

6. Sun YY, Liu HT, Du R, Li SG, Qu GG, Zhu RN, et al. Characteristic comparison of meningitis and non-meningitis of Streptococcus suis in an experimentally infected porcine model. Inflammation. 2018;5:887.
7. Yang XX, Jiang N, Wu JY, Tang RZ, Wang SJ, Wang T, Luo WG, Su L, Yang Y, Yang WZ. Clinical analysis of 75 cases of human infection with Streptococcus suis. Chinese Journal of Internal Medicine. 2007:46:764-5.

8. Beek VD, Diederik S, Lodewijk DG. Streptococcus suis meningitis in the Netherlands. J Infect. 2015:71:602-4.

9. Gu W, Miller S, Chiu CY. Clinical metagenomic next-generation sequencing for pathogen detection. Annu Rev Pathol. 2019;14:319-38.

10. Wertheim H, Nguyen HN, Taylor W, Lien TT, Ngo HT, Nguyen TQ, et al. Streptococcus suis, an important cause of adult bacterial meningitis in Northern Vietnam. PLoS ONE. 2009;4:e5973.

11. Gottschalk M, Segura M. The pathogenesis of the meningitis caused by Streptococcus suis: the unresolved questions. Vet Microbiol. 2000;76:259-72.

12. Susilawathi NM, Adi Tarini NM, Dwi Fatmawati NN, Mayura PI, Ayu Suryapraba AA, Subrata M, et al. Streptococcus suis-associated meningitis, Bali, Indonesia. Emerg Infect Dis. 2019;25:2235-42.

13. Liu LX, Li HF, Chen Y, Zhang AM. A case of septic shock secondary to Streptococcus suis infection with suspected viral meningitis. Chin J Neurol. 2017;50:681-3.

14. Simner PJ, Miller S, Carroll KC. Understanding the promises and hurdles of metagenomic next-generation sequencing as a diagnostic tool for infectious diseases. Clin Infect Dis. 2018;66:778-88.

15. Dai YY, Chen L, Chang WJ, Lu HW, Cui P, Ma XL, et al. Culture-negative Streptococcus suis infection diagnosed by metagenomic next-generation sequencing. Front Public Health. 2019;7:379.

16. Barzon L, Lavezzo E, Militello V, Toppo S, Palù G. Applications of nextgeneration sequencing technologies to diagnostic virology. Int J Mol Sci. 2011;12:7861-84

17. Besser J, Carleton HA, Gerner-Smidt P, Lindsey RL, Trees E. Next-generation sequencing technologies and their application to the study and control of bacterial infections. Clin Microbiol Infect. 2017:11:987.

18. Capobianchi MR, Giombini E, Rozera G. Next-generation sequencing technology in clinical virology. Clin Microbiol Infect. 2013;19:15-22.

19. Geng S, Mei Q, Zhu C, Fang XW, Yang TJ, Zhang L, et al. Metagenomic next-generation sequencing technology for detection of pathogens in blood of critically ill patients. Int J Infect Dis. 2020;15:447.

20. Guo LY, Li YJ, Liu LL, Wu HL, Zhou JL, Zhang Y, et al. Detection of pediatric bacterial meningitis pathogens from cerebrospinal fluid by next-generation sequencing technology. J Infect. 2019;78:323-37.

\section{Publisher's Note}

Springer Nature remains neutral with regard to jurisdictional claims in published maps and institutional affiliations.
Ready to submit your research? Choose BMC and benefit from:

- fast, convenient online submission

- thorough peer review by experienced researchers in your field

- rapid publication on acceptance

- support for research data, including large and complex data types

- gold Open Access which fosters wider collaboration and increased citations

- maximum visibility for your research: over 100M website views per year

At $\mathrm{BMC}$, research is always in progress.

Learn more biomedcentral.com/submissions 